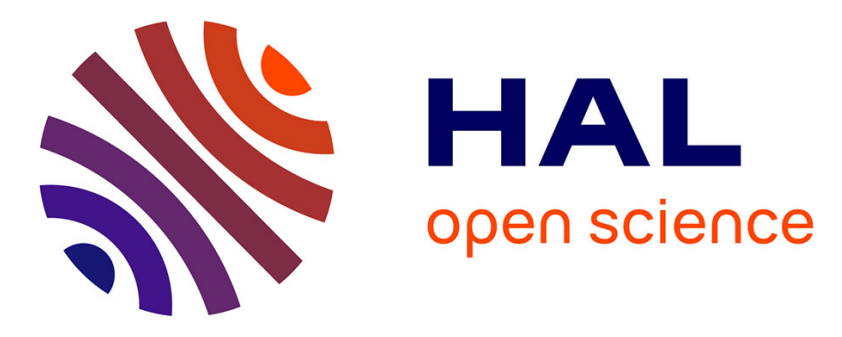

\title{
Plant community structure and nitrogen inputs modulate the climate signal on leaf traits
}

Benjamin Borgy, Cyrille Violle, Philippe Choler, Pierre Denelle, François

Munoz, Jens Kattge, Sandra Lavorel, Jessy Loranger, Bernard Amiaud, Michael Bahn, et al.

\section{To cite this version:}

Benjamin Borgy, Cyrille Violle, Philippe Choler, Pierre Denelle, François Munoz, et al.. Plant community structure and nitrogen inputs modulate the climate signal on leaf traits. Global Ecology and Biogeography, 2017, 26 (10), pp.1138-1152. 10.1111/geb.12623 . hal-01611445

\section{HAL Id: hal-01611445 \\ https://hal.science/hal-01611445}

Submitted on 7 May 2018

HAL is a multi-disciplinary open access archive for the deposit and dissemination of scientific research documents, whether they are published or not. The documents may come from teaching and research institutions in France or abroad, or from public or private research centers.
L'archive ouverte pluridisciplinaire HAL, est destinée au dépôt et à la diffusion de documents scientifiques de niveau recherche, publiés ou non, émanant des établissements d'enseignement et de recherche français ou étrangers, des laboratoires publics ou privés. 


\title{
Plant community structure and nitrogen inputs modulate the climate signal on leaf traits
}

\author{
Benjamin Borgy1,2,3* | Cyrille Violle ${ }^{1,2 *}$ | Philippe Choler ${ }^{3}$ | Pierre Denelle ${ }^{1}$ (D) | \\ François Munoz ${ }^{4}$ | Jens Kattge ${ }^{5,6}$ | Sandra Lavorel ${ }^{3}$ | Jessy Loranger ${ }^{1,7}$ | \\ Bernard Amiaud $^{8,9}$ | Michael Bahn10 | Peter M. van Bodegom ${ }^{11}$ | Henry Brisse ${ }^{12}$ | \\ Guilhem Debarros $^{13}$ | Sylvain Diquelou ${ }^{14}$ | Sophie Gachet ${ }^{12}$ | Claudy Jolivet ${ }^{15}$ | \\ Servane Lemauviel-Lavenant ${ }^{14}$ | Alexis Mikolajczak ${ }^{16}$ | Jean Olivier ${ }^{13}$ | \\ Jenny Ordoñez ${ }^{11}$ | Patrice de Ruffray ${ }^{17}$ | Nicolas Viovy ${ }^{18}$ | Eric Garnier ${ }^{1}$ \\ ${ }^{1}$ Centre d'Ecologie Fonctionnelle et Evolutive (UMR 5175), CNRS - Université de Montpellier - Université Paul-Valéry Montpellier - EPHE, 1919 route de Mende, \\ 34293 Montpellier Cedex 5, France \\ ${ }^{2}$ CESAB/FRB, Domaine du Petit Arbois, Avenue Louis Philibert, 13545 Aix-en-Provence, France \\ ${ }^{3}$ University of Grenoble Alpes - CNRS, LECA, 38000 Grenoble, France \\ ${ }^{4}$ Montpellier University, AMAP, Boulevard de la Lironde, TA A-51/PS2, 34398 Montpellier, France \\ ${ }^{5}$ Max Planck Institute for Biogeochemistry, Hans Knoell Straße 10, 07745 Jena, Germany \\ ${ }^{6}$ German Centre for Integrative Biodiversity Research (iDiv) Halle-Jena-Leipzig, Deutscher Platz 5e, 04103 Leipzig, Germany \\ 7Université de Sherbrooke, 2500 blv. de l'Université, Sherbrooke, Québec, Canada 2R1 J1K \\ ${ }^{8}$ Ecologie et Ecophysiologie Forestières, Université de Lorraine, UMR 1137, 54500 Vandoeuvre-les-Nancy, France \\ ${ }^{9}$ Ecologie et Ecophysiologie Forestières, INRA, UMR 1137, 54280 Champenoux, France \\ ${ }^{10}$ Institute of Ecology, University of Innsbruck, Sternwartestraße 15, A-6020 Innsbruck, Austria \\ ${ }^{11}$ Department of Systems Ecology, Institute of Ecological Science, VU University Amsterdam, 1081 HV Amsterdam, The Netherlands \\ ${ }^{12}$ IMBE, Aix Marseille University, Fac Sci St Jerome, UMR 6116, 13397 Marseille 20, France \\ ${ }^{13}$ Fédération des Conservatoires Botaniques Nationaux, 93511 Montreuil-sous-Bois, France \\ ${ }^{14}$ Ecophysiologie Végétale Agronomie et nutritions NCS, INRA, Université de Caen, UMR 950, Esplanade de la Paix, 14032 Caen, France \\ ${ }^{15}$ US1106 InfoSol, INRA, 45075 Orléans, France \\ ${ }^{16}$ domaine de Charance, Conservatoire Botanique National Alpin, 05000 Gap Cedex 5, France \\ ${ }^{17}$ Institut de Biologie Moléculaire des Plantes, CNRS, 67084 Strasbourg, France \\ ${ }^{18}$ Laboratoire des Sciences du climat et de l'Environnement (UMR 8212 CEA/CNRS/UVSQ), Orme des Merisiers, CEA Saclay, 91191 Gif-sur-Yvette Cedex, France
}

\section{Correspondence}

Eric Garnier, Centre d'Ecologie

Fonctionnelle et Evolutive (UMR 5175),

CNRS, Université de Montpellier, Université

Paul-Valéry Montpellier, EPHE, 1919 route

de Mende, 34293 Montpellier Cedex 5,

France.

Email: eric.garnier@cefe.cnrs.fr

Funding information

French Foundation for Research on

Biodiversity; DIVERSITAS/Future Earth and

the German Centre for Integrative

\section{Abstract}

Aim: Leaf traits strongly impact biogeochemical cycles in terrestrial ecosystems. Understanding leaf trait variation along environmental gradients is thus essential to improve the representation of vegetation in Earth system models. Our aims were to quantify relationships between leaf traits and climate in permanent grasslands at a biogeographical scale and to test whether these relationships were sensitive to (a) the level of nitrogen inputs and (b) the inclusion of information pertaining to plant community organization.

Location: Permanent grasslands throughout France. 
Methods: We combined existing datasets on climate, soil, nitrogen inputs (fertilization and deposition), species composition and four traits, namely specific leaf area, leaf dry matter content and leaf nitrogen and phosphorus concentrations, for 15,865 French permanent grasslands. Trait-climate relationships were tested using the following four climatic variables available across 1,833 pixels $(5 \mathrm{~km} \times 5 \mathrm{~km}$ ): mean annual temperature (MAT) and precipitation (MAP), and two indices accounting for the length of the growing season. We compared these relationships at the pixel level using either using community-level or species' trait means.

Results: Our findings were as follows: (a) leaf traits related to plant nutrient economy shift consistently along a gradient of growing season length accounting for temperature and soil water limitations of plant growth (GSL $\mathrm{tw}_{\mathrm{w}}$ ); (b) weighting leaf traits by species abundance in local communities is pivotal to capture leaf trait-environment relationships correctly at a biogeographical scale; and (c) the relationships between traits and $\mathrm{GSL}_{t w}$ weaken for grasslands with a high nitrogen input.

Main conclusions: The effects of climate on plant communities are better described using composite descriptors than coarse variables such as MAT or MAP, but appear weaker for highnitrogen grasslands. Using information at the community level tends to strengthen trait-climate relationships. The interplay of land management, community assembly and bioclimate appears crucial to the prediction of leaf trait variations and their effects on biogeochemical cycles.

\section{KEYWORDS}

community functional structure, environmental gradients, fertilization, functional biogeography, functional diversity, growing season length, land management, permanent grasslands, plant traits

\section{1 | INTRODUCTION}

Leaf traits strongly impact the nutrient, carbon and water cycles of terrestrial ecosystems (Chapin et al., 2000; Wang et al., 2012); for example, primary productivity across ecosystems is related to foliar nitrogen concentration (Lavorel et al., 2011; Pontes, Soussana, Louault, Andueza, \& Carrère, 2007), and litter decomposition to leaf dry matter content (Fortunel et al., 2009; Pakeman, Eastwood, \& Scobie, 2011). Scaling information from traits, which are usually measured at the population or species level, to the ecosystem requires accounting for plant community organization (which results from community assembly processes; Lavorel \& Garnier, 2002; Suding et al., 2008), which appears to be a pivotal step to predict terrestrial biogeochemistry (Grime, 1998; reviewed by Garnier, Navas, \& Grigulis, 2016). These advances contrast with the current representation of vegetation in Earth system models (e.g., Verheijen et al., 2013), in which (a) the existing trait variation within broadly defined plant functional types (e.g., $C_{3}$ and $C_{4}$ herbs, deciduous and evergreen trees) is largely ignored (but see Wang et al., 2012), and (b) the plant community, although a relevant level of organization to capture the relationships between traits, environments and ecosystem properties, is overlooked.

So far, studies of leaf trait responses to climate variables over biogeographical gradients reveal inconsistencies (Reich, 2014; Violle, Reich, Pacala, Enquist, \& Kattge, 2014). For example, specific leaf area (SLA; the ratio of leaf area to leaf mass) is found to increase (Read, Moorhead, Swenson, Bailey, \& Sanders, 2014; Simpson, Richardson, \& Laughlin, 2016), decrease (Moles et al., 2014; Wright et al., 2005) or remain invariant (Onoda et al., 2011) with increasing mean annual temperature (MAT). Likewise, although some studies find an increase in SLA with mean annual precipitation (MAP) (Moles et al., 2014; Wright et al., 2004), others show a lack of variation (Sandel et al., 2010) or even a slight decrease (Wright et al., 2005 for deciduous species) with MAP. Such inconsistent patterns might arise for several reasons. First, the climate variables used in these studies might be poor descriptors of the actual bioclimate sensed by plants (van Ommen Kloeke, Douma, Ordoñez, Reich, \& van Bodegom, 2012). Second, analyses across biogeographical and bioclimatic gradients might be influenced by the presence or absence of functional groups (e.g., evergreen versus deciduous) or species with contrasting leaf traits whose response to climate might differ in strength and even direction (Kikuzawa, Onoda, Wright, \& Reich, 2013; Wright et al., 2005). Third, large-scale studies generally tend to ignore local drivers, such as soil nutrient availability and land use, which critically affect leaf traits (Cunningham, Summerhayes, \& Westoby, 1999; Hodgson et al., 2011; Ordoñez et al., 2009; but see Simpson et al., 2016). Finally, with very few exceptions (Simpson et al., 2016; Wang et al., 2016), studies conducted at large spatial scales ignore the fact that populations of plant species are organized locally in communities, in which they occur almost always at strongly uneven abundances. In the majority of such studies, whether a species is abundant or rare is not accounted for, although it can be hypothesized that the fit between traits and the environment is stronger for abundant species (Cingolani, Cabido, Gurvich, Renison, \& Díaz, 2007; Grime, 1998; Muscarella \& Uriarte, 2016). Furthermore, to inform a future generation of Earth system models, robust relationships between 
climate, soil and traits are required that account for effects of species abundance within communities (encapsulated into so-called 'community-weighed means' of traits, hereafter CWM) (Garnier et al., 2016; Reich, 2014). CWMs capture the fact that traits of dominant species have a stronger effect on ecosystem properties than traits of species with low abundance (Garnier et al., 2004; Grime, 1998). To date, however, very few studies have tested to what extent climate and land management control the CWM of leaf traits at a biogeographical scale (but see Pakeman et al., 2009 for an exception).

To investigate the interplay between climate, land management and leaf traits, we assembled a dataset of unprecedented coverage across French permanent grasslands, a case study for semi-natural temperate grasslands dominated by $\mathrm{C}_{3}$ herbaceous species. Based on 15,865 botanical relevés and 1,939 species, leaf trait variations were characterized across 1,833 pixels at a $5 \mathrm{~km} \times 5 \mathrm{~km}$ grid resolution. Considering four traits of the leaf economics spectrum (Reich, 2014; Shipley, Lechowicz, Wright \& Reich, 2006; Wright et al., 2004), namely SLA, mass-based leaf nitrogen and phosphorus concentrations (LNC and LPC, respectively) and leaf dry matter content (LDMC), we addressed the following questions. (a) Which bioclimatic descriptor best captures the spatial variation of leaf traits across the investigated biogeographical gradients? (ii) What is the benefit of accounting for plant community structure when examining these trait-environment relationships? (c) To what extent do local land management drivers modulate the effect of bioclimatic drivers on trait variation?

\section{2 | METHODS}

\section{1 | Vegetation relevés, species distribution and trait data}

We used several sources to assemble a dataset of 51,485 georeferenced vegetation relevés (i.e., a list of species with local abundance) in French permanent grasslands (Appendix, Figure S1 in the Supporting Information and see Violle et al., 2015 for further details). The data consist of visually estimated relative cover of all present species in homogeneous plots, usually from 25 to $100 \mathrm{~m}^{2}$, using a six-level abundance scale following the Braun-Blanquet method (BraunBlanquet, 1932): 0\%-1\%, 1\%-5\%, 5\%-25\%, 25\%-50\%, 50\%-75\% and $75 \%-100 \%$. We used the median of each class to estimate species' local abundance within the community. As a result of varying taxonomic conceptions among authors, we merged all intraspecific ranks (subspecies and varieties) to the species level. In addition to these relevés, the spatial distribution of 2,464 plant species was retrieved from the electronic atlas of the French flora (http://siflore.fcbn.fr). These data, for which the original scale of recording is the administrative territory of councils ('cantons'), were aggregated at a resolution level of 5 $\mathrm{km} \times 5 \mathrm{~km}$.

We extracted individual values of SLA (in in square metres per kilogram), LDMC (in milligrams per gram), LNC (in milligrams per gram) and LPC (in milligrams per gram) from the TRY database (Kattge et al., 2011), complemented by data from regional databases (Appendix) to calculate a mean trait value per species. Trait data from artificial conditions (e.g., greenhouses or growth chambers) were not retained for this analysis. Previous analyses have shown that, in spite of a certain degree of intraspecific variation (e.g., Albert et al., 2010; Kichenin, Wardle, Peltzer, Morse, \& Freschet, 2013), species and community rankings for traits values measured on site and in TRY remained generally consistent (Borgy et al., 2017; Kazakou et al., 2014). In addition, a recent meta-analysis has demonstrated that the relative amount of intraspecific compared with interspecific variation decreased with increasing spatial extent (Siefert et al., 2015). We thus assumed that taking a mean trait value per species does not impede the detection of trait-environment relationships at the biogeographical scale of the present study. Further details on trait data availability can be found in the paper by Violle et al. (2015).

\section{2 | Bioclimate and soil data}

Monthly means of air temperatures (in degrees Celsius) and monthly sums of rainfall (in millimetres) for the 1961-1990 period over the French metropolitan territory were provided by the $1 \mathrm{~km}$ resolution gridded dataset of MétéoFrance (Benichou \& Le Breton, 1987). Incoming net radiation accounting for topographic effects was calculated at the French national level according to Piedallu and Gégout (2008). A one-bucket water-balance model was implemented to estimate the dynamics of soil available water content (AW; in millimetres). This model used a Turc-based (Turc, 1961) estimate of potential evapotranspiration (PET; in millimetres). Soil water-holding capacity (WHC) was derived from the 1/1,000,000-scale Soil Geographical Database of France, following the methodology of Le Bas, King, and Daroussin (1997) and using the pedotransfer functions from Al Majou, Bruand, Duval, Le Bas, and Vautier (2008). All climate and soil variables were spatially interpolated to the $5 \mathrm{~km} \times 5 \mathrm{~km}$ grid cell resolution to match vegetation data. Monthly climate time series were interpolated at a daily time step to calculate growing season length (GSL). For each pixel, AW of day $n$ equalled AW of day $n-1$, plus precipitation and minus PET. AW was bound between 0 and WHC. The model was run for 10 years with the same climate forcing to estimate the yearly time course of AW. Growing season length $\left(\mathrm{GSL}_{\mathrm{tw}}\right)$ corresponded to the number of days in the year for which (a) mean daily temperature was above $5{ }^{\circ} \mathrm{C}$ and (b) the ratio AW/WHC was > 0.2. We also estimated a GSL based only on temperature $\left(\mathrm{GSL}_{t}\right)$ or on soil water content $\left(\mathrm{GSL}_{\mathrm{w}}\right.$; Figures $\mathrm{S} 2$ and S3 in Supporting Information).

To compare the climatic space covered by permanent grasslands in France with that covered by grasslands in Europe, MAT (in degrees Celsius) and MAP (in millimetres) were obtained at the European scale from the WorldClim global climate data base (http://www.worldclim. org/current) extracted at a $30 \mathrm{~s}$ resolution and aggregated at 5 $\mathrm{km} \times 5 \mathrm{~km}$ to match the final grid cell resolution.

\section{3 | Nitrogen input data}

Nitrogen input was the sum of organic fertilization, mineral fertilization and nitrogen deposition. Data were obtained from the census NopoluAgri information system of the French Ministry of Agriculture (http:// 
www.statistiques.developpement-durable.gouv.fr). These data were collected in 2010 through national surveys of the amount of nitrogen excreted by herbivores and from statistics of the fertilization industry sector. The dataset for nitrogen atmospheric deposition in 2010 was provided by the European Monitoring and Evaluation Program (http:// www.emep.int/mscw/SR_data/sr_grid.html). Given that the current mode of fertilization of French permament grasslands has been in practice since the beginning of the 1980s (Huyghe, 2009; PalacioRabaud, 2000), we assumed that these nitrogen input data are representative of the average input corresponding to the period over which botanical relevés were retained for the analyses (see section 2.4 below). These data were available for each French council, whose mean area is $c .8 \mathrm{~km}^{2}$, similar to the order of magnitude of the climate grid cell. Given that these data represent coarse estimates of nitrogen

\begin{tabular}{l} 
Organization of data \\
\hline \begin{tabular}{l|l|l|l|l|l|}
\hline Species & a & b & c & d & e \\
\hline $\begin{array}{l}\text { Mean trait } \\
\text { value }\end{array}$ & 2 & 5 & 3 & 7 & 4 \\
\end{tabular}
\end{tabular}

\section{Community data: vegetation relevés}

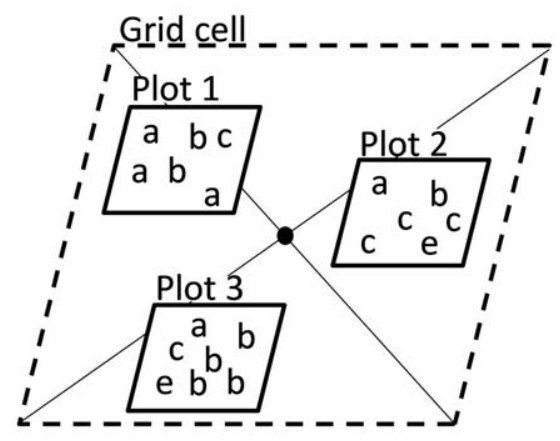

NB: In a pixel, every plot gets the same coordinates which correspond to the centroïd of the pixel.

\section{Grid level calculation}

\section{Community Weighted Mean: CWM}

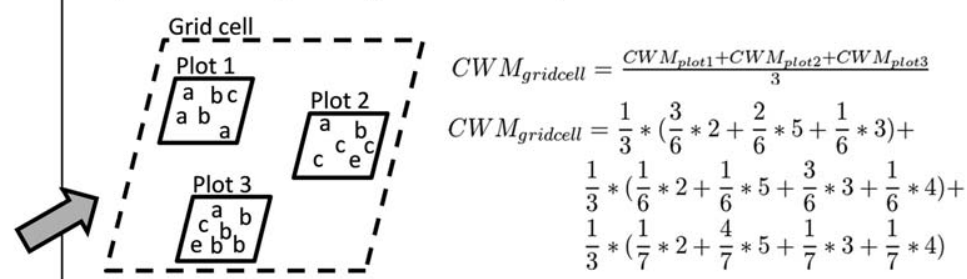

\section{Community Arithmetic Mean: CArM}

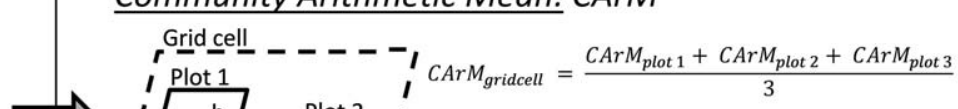

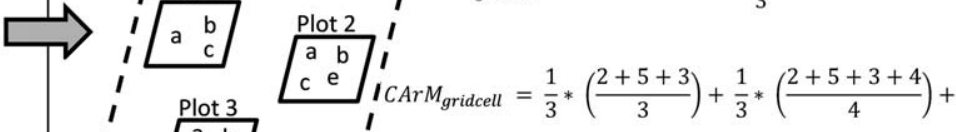

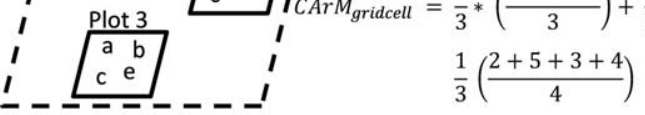

Grid Cell Mean: GCM_r

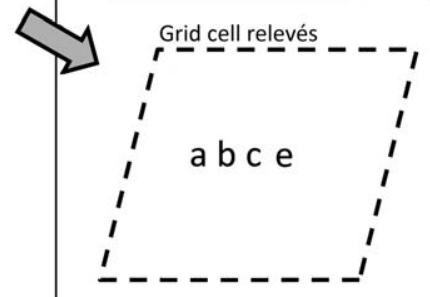

$$
G C M_{-r}=\frac{2+5+3+4}{4}
$$

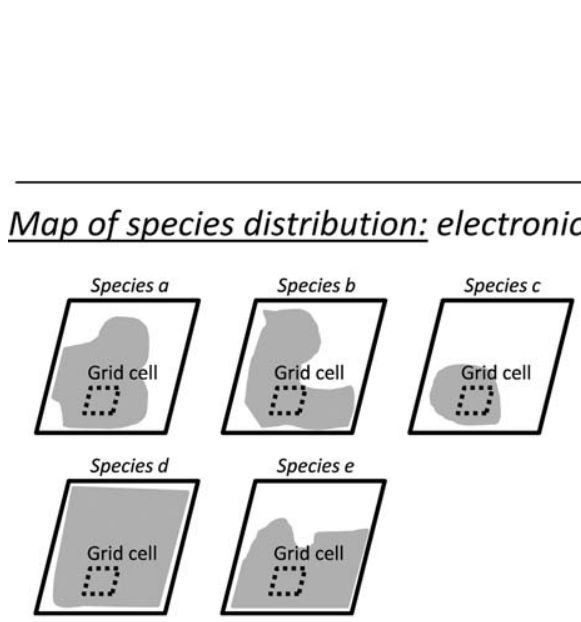

I

FIGURE 1 Schematic representation of the four methods used to calculate aggregated trait values. Metrics used to calculate average trait values either take community organization into account (CArM and CWM) or not (GCM_r and GCM_a). For the calculation of community arithmetic mean (CArM), a mean value was calculated for each trait and relevé by giving an equal weight to each species. For the community-weighted mean (CWM) calculation, a mean value was calculated for each trait and relevé by weighting the species trait values by the relative abundances of these species within the community. Averages for these two metrics were then calculated at the $5 \mathrm{~km} \times 5 \mathrm{~km}$ grid cell level, by giving an equal weight to each relevé within each cell. For metrics that do not account for community organization, trait values of all species occurring in a grid cell, derived from either vegetation relevés (GCM_r) or distribution maps (GCM_a), were averaged, with an equal weight given to each species. There is therefore one value per $5 \mathrm{~km} \times 5 \mathrm{~km}$ grid cell for each of the four metrics. The figure shows examples of calculations for the four metrics using hypothetical trait values for five species; the number of times a letter representing a species is repeated in a plot amounts to the abundance of this species 
inputs in grasslands at the grid cell level (see section 2.4 below and Figure S4 in Supporting Information), we did not use these as a continuous variable, but rather subdivided grasslands into two classes corresponding to low ( $<73 \mathrm{~kg}[\mathrm{~N}] /$ ha, the median value of inputs) and high (> $73 \mathrm{~kg}[\mathrm{~N}] / \mathrm{ha})$ inputs.

\section{4 | Data analyses}

Four averaging metrics were used to derive aggregated values of leaf traits (Figure 1). The first two were calculated at the grid cell level and do not explicitly take into account the organization of species in communities: (a) a grid cell mean (GCM_a hereafter; Figure 1) was calculated by averaging trait values of all species occurring in a $5 \mathrm{~km} \times 5 \mathrm{~km}$ grid cell (species presence in a grid cell derived from the electronic atlas of the French flora), irrespective of plant community organization, and with equal weight given to each species, and (b) a GCM where the species presence occurring in a $5 \mathrm{~km} \times 5 \mathrm{~km}$ grid cell are derived from the geo-referenced relevés (GCM_r hereafter). Two additional metrics were calculated at the community level: these are (c) community arithmetic means (CArM) assessed for each relevé by calculating a mean trait value in which equal weight was given to each species, and (d) community-weighted means (CWM), calculated as for CArM, but in which trait values were weighted by the relative abundances of species within the community (Borgy et al., 2017; Garnier et al., 2004). In order to be able to compare trait-climate relationships for all four metrics and obtain an accurate estimate of community-level metrics at the pixel level (cf. Borgy et al., 2017), CArM and CWM values were then averaged for all botanical relevés available within a $5 \mathrm{~km} \times 5 \mathrm{~km}$ grid cell (Figure 1). Overall, there was therefore a single value per pixel for each of the four metrics compared. To acknowledge the fact that the

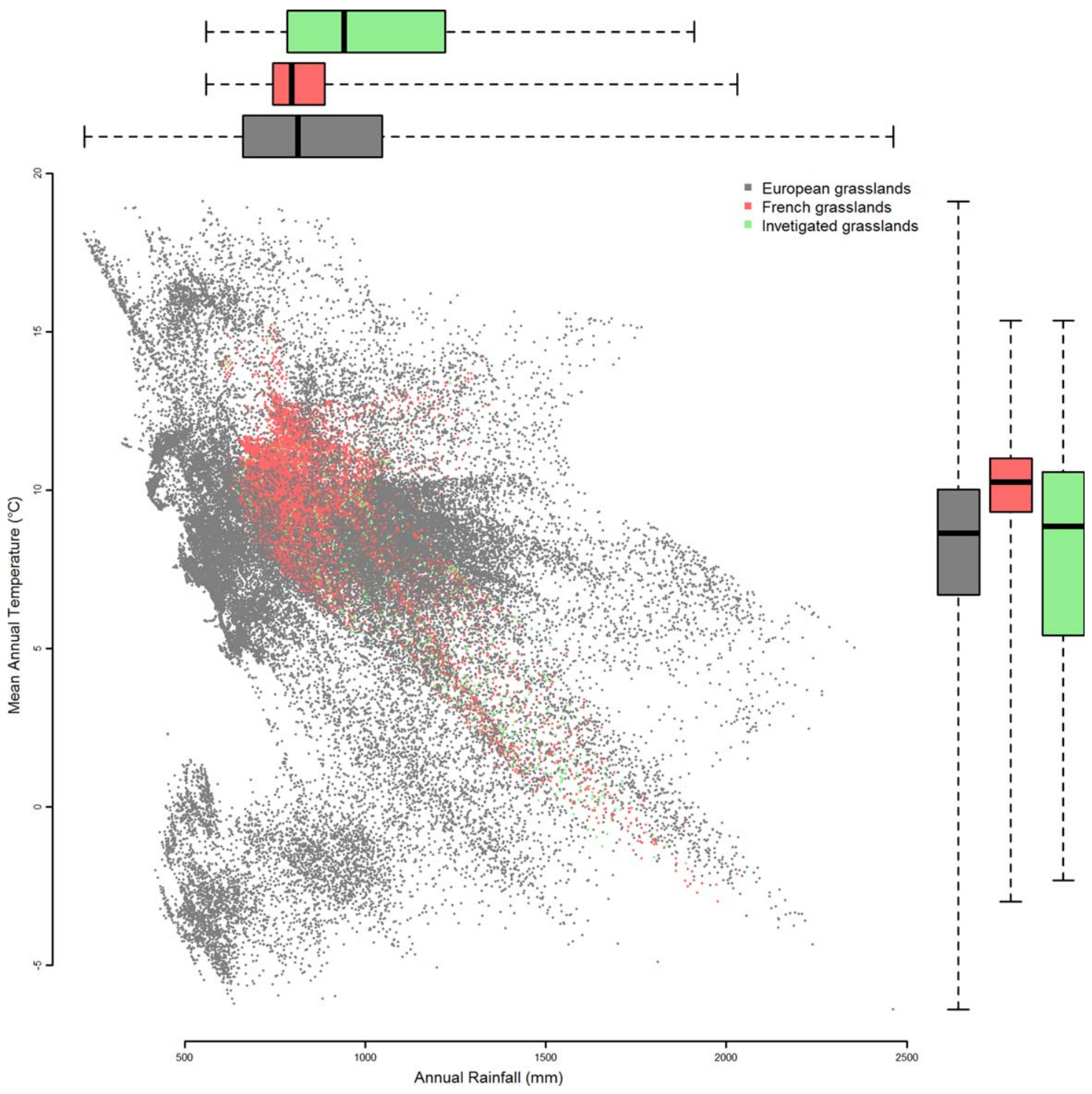

FIGURE 2 Climate envelope of grasslands in Europe and in France. Distribution of mean annual temperature (MAT; in degrees Celsius) and mean annual precipitation (MAP; in millimetres) covered by European grasslands (black), French grasslands (red) and the French grasslands investigated in this study (green). Distributions of quartiles are shown at the top and at the right-hand side of the figure for each dataset and each climate variable 
climate signal on traits is more likely to be detected for pixels with a high proportion of grasslands, values of the four metrics were weighted by the proportion of grassland in each pixel.

Only relevés conducted after 1980 were retained, and because trait values were not available for all species (cf. Violle et al., 2015), we removed relevés if the proportion cover $\left(P_{\text {Cover }}\right)$ of species included for the calculation of the CWM of at least one trait was $<60 \%$ (Pakeman \& Quested, 2007; see Borgy et al., 2017 for a detailed discussion on issues related to threshold values). Grid cells containing at least $20 \%$ grassland cover were retained (cf. Supporting Information Figure S1), and grid cells with fewer than three relevés were discarded (see Borgy et al., 2017; Violle et al., 2015). The final dataset based on vegetation relevés included values of the four averaging metrics calculated for 1,833 pixels, representing 15,865 relevés and 1,939 species (with a median of five relevés per pixel). Of these, 9,692 relevés grouped into 918 pixels corresponded to low-nitrogen-input grasslands, and 6,173 relevés grouped into 915 pixels corresponded to high-nitrogen-input grasslands. The dataset based on the electronic atlas, which corresponds to the approach most used in functional biogeography (e.g., Swenson et al., 2012), included 1,833 pixels.

We used generalized least-squares (GLS) models to test the relationships between metrics of aggregated leaf traits and climatic variables (MAT, MAP, GSLt and GSLtw), while acknowledging the influence of spatial autocorrelation using the R package nlme. For each trait, we built alternative GLS models with all climatic predictors but different spatial structures. One of the models did not include spatial autocorrelation structure, whereas the other four included respectively a spherical, rational quadratic, Gaussian or exponential spatial autocorrelation structure. We selected the most appropriate spatial structure based on the lowest Akaike information criteria (Zuur, leno, Walker, Saveliev, \& Smith, 2009). For the four traits considered here, the quadratic ratio spatial structure was the most appropriate spatial structure in GLS models.

Given that we used GLS models, the goodness of fit of relationships was assessed by calculating the square of the correlation coefficient (so-called pseudo- $R^{2}$ ) between the observed and the fitted variables (Hosmer, Lemeshow, \& Sturdivant, 2013, p. 182). Analyses were conducted for the whole set of grasslands and by sorting grasslands according to the level of nitrogen inputs (low or high; see above). For each model, we assessed the slope differences between the two nitrogen input levels using ANOVAs. All statistical operations were performed in R 3.3.2 (R Development Core Team, 2016).

Trait-environment relationships are shown as figures in the main body of the paper and Supporting Information for selected variables, and as a Shiny application for all combinations, available at https:// shiny.cefe.cnrs.fr/trait_environment_relationships (see Supporting Information Application S1 for details).

\section{3 | RESULTS}

Permanent grasslands in France are found over a broad climatic range, from 600 to $>2,000 \mathrm{~mm} \mathrm{MAP}$ and from -3 to $15.5^{\circ} \mathrm{C}$ MAT (red cloud in the bivariate plot shown in Figure 2); the ranges in precipitations and temperatures covered by the 1,833 pixels of the present study correspond respectively to 91 and $96 \%$ of these ranges (green cloud in Figure 2). This climate envelope encompassed nearly $80 \%$ of the MAT range and $57 \%$ of the MAP range covered by European grasslands (grey cloud in Figure 2).

Whatever the metrics used to calculate aggregated trait values, the GSL that integrates both temperature and soil water limitation on plant growth $\left(\mathrm{GSL}_{\mathrm{tw}}\right)$ was the best descriptor of leaf trait variation (Table 1). Compared with $\mathrm{GSL}_{\mathrm{tw}}$, the GSL not accounting for soil water limitations $\left(\mathrm{GSL}_{\mathrm{t}}\right)$, MAT and MAP explained a lower proportion of leaf trait variation (Supporting Information Application S1). Among the two latter descriptors, trait variations were more strongly related to MAT than to MAP, for all four metrics (Table 1). SLA, LNC and LPC were positively related to $\mathrm{GSL}_{t w}, \mathrm{GSL}_{t}$ and MAT, and negatively to MAP (Table 1, Figure 3, and Figure S5 and Application S1 in Supporting Information); opposite relationships were found for LDMC.

TABLE 1 Pseudo- $R^{2}$ and direction of relationships of linear models relating leaf traits to climate descriptors

\begin{tabular}{|c|c|c|c|c|c|}
\hline Trait & Averaging metrics & MAT & MAP & $\mathrm{GSL}_{\mathrm{t}}$ & $\mathrm{GSL}_{\mathrm{tw}}$ \\
\hline \multirow{4}{*}{ SLA } & CWM & $0.22(+)$ & $0.038(-)$ & $0.23(+)$ & $0.32(+)$ \\
\hline & CArM & $0.20(+)$ & $0.018(-)$ & $0.21(+)$ & $0.31(+)$ \\
\hline & GCM_r & $0.21(+)$ & $0.017(-)$ & $0.21(+)$ & $0.30(+)$ \\
\hline & GCM_a & $0.26(+)$ & $0.0011(-)$ & $0.23(+)$ & $0.38(+)$ \\
\hline \multirow{4}{*}{ LDMC } & CWM & $0.16(-)$ & $0.069(+)$ & $0.17(-)$ & $0.21(-)$ \\
\hline & CArM & $0.17(-)$ & $0.048(+)$ & $0.17(-)$ & $0.19(-)$ \\
\hline & GCM_r & $0.15(-)$ & $0.055(+)$ & $0.15(-)$ & $0.14(-)$ \\
\hline & GCM_a & $0.20(-)$ & $0.15(+)$ & $0.21(-)$ & $0.12(-)$ \\
\hline \multirow{4}{*}{ LNC_m } & CWM & $0.11(+)$ & $0.035(-)$ & $0.12(+)$ & $0.16(+)$ \\
\hline & CArM & $0.08(+)$ & $0.0098(-)$ & $0.08(+)$ & $0.14(+)$ \\
\hline & GCM_r & $0.061(+)$ & $0.012(-)$ & $0.063(+)$ & $0.11(+)$ \\
\hline & GCM_a & $0.041(+)$ & $0.017(-)$ & $0.059(+)$ & $0.11(+)$ \\
\hline \multirow{4}{*}{ LPC_m } & CWM & $0.14(+)$ & $0.041(-)$ & $0.15(+)$ & $0.19(+)$ \\
\hline & CArM & $0.16(+)$ & $0.035(-)$ & $0.16(+)$ & $0.23(+)$ \\
\hline & GCM_r & $0.14(+)$ & $0.026(-)$ & $0.14(+)$ & $0.21(+)$ \\
\hline & GCM_a & $0.092(+)$ & $0.0091(-)$ & $0.11(+)$ & $0.19(+)$ \\
\hline
\end{tabular}

$\mathrm{GSL}_{\mathrm{t}}=$ growing season length accounting for temperature limitation; $\mathrm{GSL}_{\mathrm{tw}}=$ growing season length accounting for both temperature and soil water limitations (for further details, see the Methods and Figure S3 in Supporting Information); LDMC = leaf dry matter content; LNC_m = massbased leaf nitrogen concentration; LPC_m = mass-based leaf phosphorus concentration; $\mathrm{MAP}=$ mean annual precipitation; $\mathrm{MAT}=$ mean annual temperature; SLA = specific leaf area. Note. Results are given for the four averaging metrics used (see Methods and Figure S4 in Supporting Information): community arithmetic means (CArM), community-weighted means (CWM) and grid cell means calculated from relevés (GCM_r) and from the electronic atlas of the French flora (GCM_a). The direction of the relationship is given in parentheses. For all models, $p$-value $<10^{-3} ; n=1,833$ data points were included in the models. 

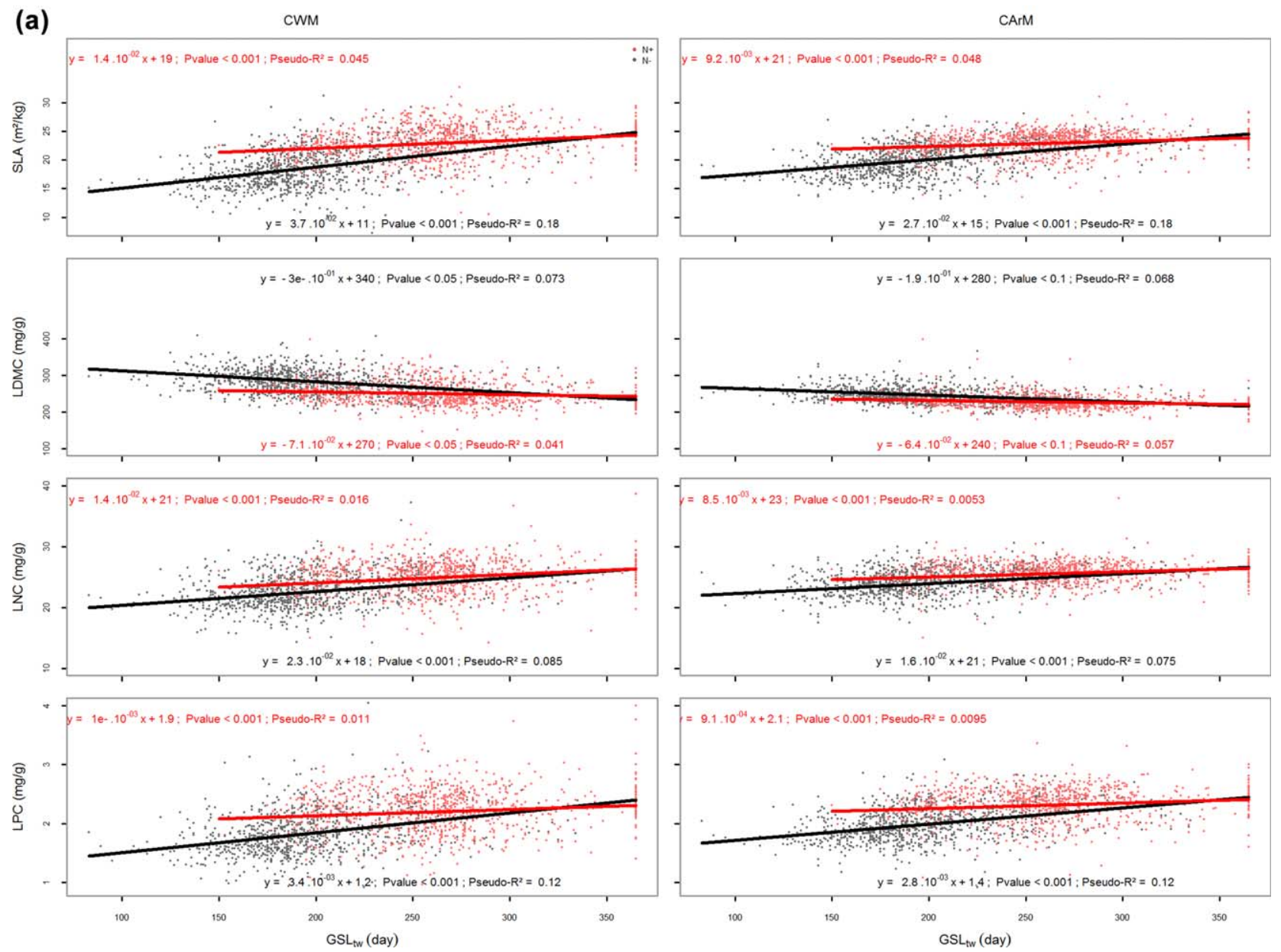

FIGURE 3 (a) and (b) Relationships between growing season length (GSL $\mathrm{tw}_{w}$ ) and leaf traits with different levels of nitrogen input. GSL $\mathrm{t}_{\mathrm{tw}}$ accounts for growth limitations by temperature and soil water availability (see Figure S2 in Supporting Information). In (a), average leaf traits were calculated taking community organization into account, whereas this is not the case in (b) (see Figure 1 for details). Red and black dots and lines correspond respectively to high (915 pixels grouping 6,173 relevés) and low (918 pixels grouping 9,692 relevés) levels of nitrogen input, as defined by the median of nitrogen input distribution (see Methods section). In (a), the averaging metrics are as follows: community-weighted means (CWM; four panels on the left) and community arithmetic means (CArM; four panels on the right), which average data for all available botanical relevés within a $5 \mathrm{~km} \times 5 \mathrm{~km}$ grid cell. In (b), the averaging metrics are as follows: grid cell means based on vegetation relevés (GCM_r; four panels on the left) and grid cell means based on the electronic atlas of the French flora (GCM_a; four panels on the right), which average trait values of all species occurring in a grid cell irrespective of plant community organization.

LDMC = leaf dry matter content; LNC = mass-based leaf nitrogen concentration; LPC = mass-based leaf phosphorus concentration; SLA = specific leaf area. Equations of linear regressions between traits and climatic descriptors are given in each panel for each nitrogen level (red characters: high nitrogen; black characters: low nitrogen). For each trait and averaging metrics, an ANCOVA was run to test for the difference between slopes of the two nitrogen input levels. Results are displayed in each panel, showing the value of $F$ statistics and its significance. ${ }^{* *} p<.001 .{ }^{* *} p<.01 .{ }^{*} P<.05 .{ }^{+} p<0.1 .{ }^{n s} p>.1$. The significance level of each individual regression is given in Supporting Information Application S1

We also investigated whether nitrogen input modulates the climate signal on leaf traits. Nitrogen input had significant impacts on trait values irrespective of climate. For any given value of $\mathrm{GSL}_{\mathrm{tw}}$, our results indicated significant upward shifts in SLA, LNC and LPC and a downward shift in LDMC in high-nitrogen-input grasslands (Figure 3). Consequently, the ability to detect significant trait-climate relationships was dependent upon the level of these inputs; under low nitrogen inputs the leaf traits were strongly related to $\mathrm{GSL}_{\mathrm{tw}}$, whereas under high nitrogen inputs the leaf traits were slightly or not significantly responsive to $\mathrm{GSL}_{\mathrm{tw}}$ (Figure 3). This translates into significantly higher slope values of trait-environment relationships for low-nitrogen-input compared with high-nitrogen-input grasslands for all metrics apart from GCM_a (Figure 4 and Supporting Information Application S1).

Finally, we tested whether the strength of the climate signal on leaf traits differed when trait means were obtained by accounting for species abundances in plant communities (calculations of CWM values), neglecting species abundances (calculations of CArM values), or by simply averaging trait values of all species occurring within a grid cell (calculation of GCM_r and GCM_a values; see Figure 1). Results for all combinations of (climate descriptors $\times$ metrics) analysed separately for the two nitrogen levels are 

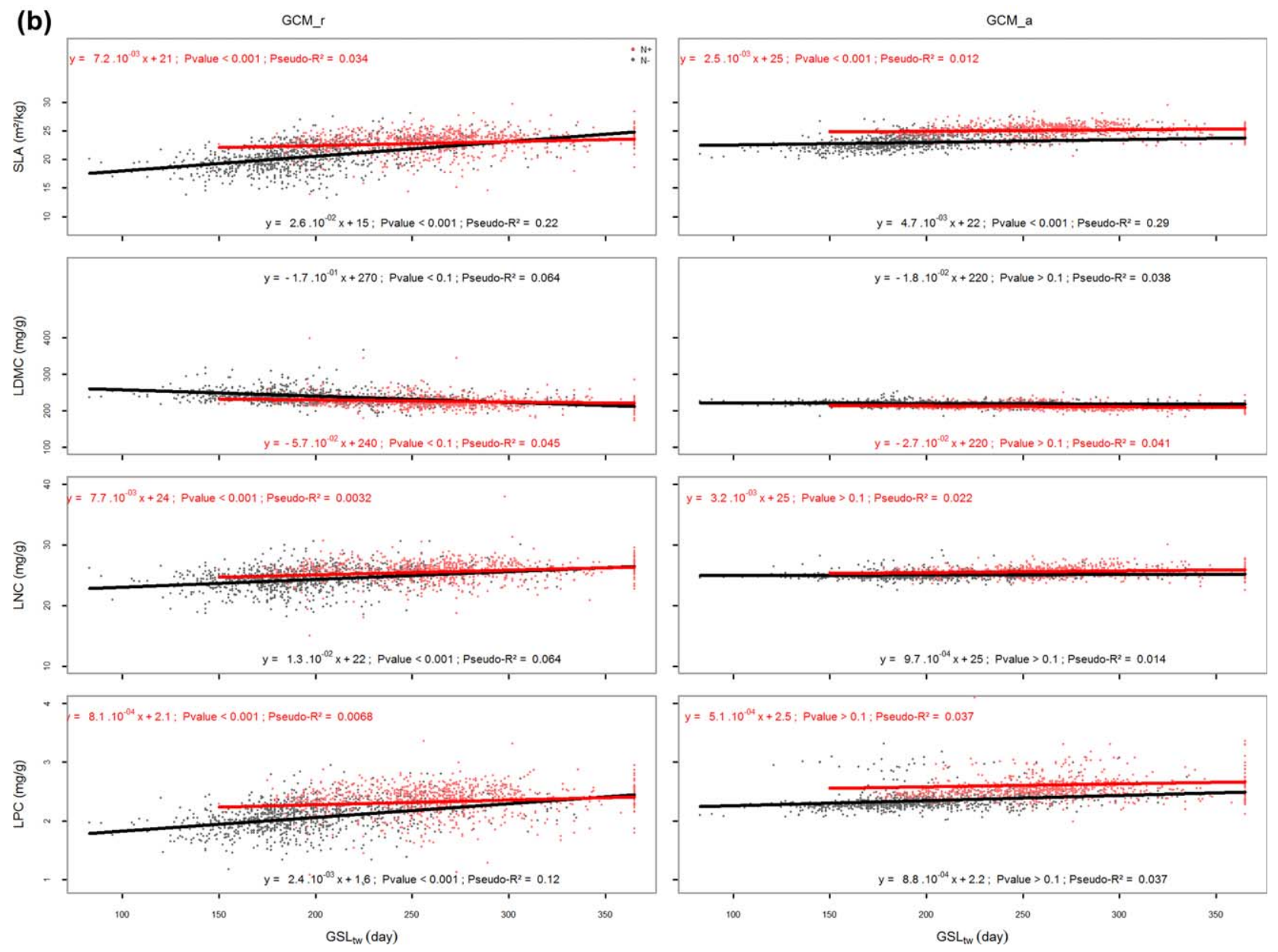

FIGURE 3 Continued

provided in the Supporting Information Application S1. Here, we focus on the relationships with $\mathrm{GSL}_{\mathrm{tw}}$, the best climate predictor of trait-environment relationships. Overall, for a fixed trait $\times$ environmental descriptor combination, pseudo- $R^{2}$ values were comparable for all metrics (Table 1 , Figure 3 and Supporting Information Application S1), but slopes differed substantially among metrics. These were generally steeper for CWMs (Figures 3 and 4 and Supporting Information Application S1). The same conclusion generally held when $\mathrm{GSL}_{\mathrm{tw}}-\mathrm{CWM}$ and $\mathrm{GSL}_{\mathrm{tw}}-\mathrm{GCM} \mathrm{r}$ relationships were compared, with generally even gentler slopes for the latter (Figure 4). There was much less difference between the slopes of the $\mathrm{GSL}_{\mathrm{tw}}-\mathrm{CArM}$ and $G S L_{t w}-G C M \_r$ relationships. Finally, the slopes of the $G L_{t w}-G C M$ relationships assessed with floristic relevés (GCM_r) and species distribution (GCM_a) were steeper for GCM_r (Figures 3 and 4). The spread of data points around the regression lines was substantially lower for the $\mathrm{GSL}_{\mathrm{tw}}$-GCM_a relationships than for the three other metrics (compare, in particular, the $\mathrm{GSL}_{\mathrm{tw}}-\mathrm{LNC}$ relationships for the four metrics in Figure 3).

\section{4 | DISCUSSION}

The climate space encompassed by the grasslands studied here is relatively wide and covers a fairly broad extent of the climate space covered by European grasslands in particular (Figure 2) and by temperate grasslands in general (cf. Sala, Austin, \& Vivanco, 2001). This gives some confidence as to the generality of the trait-climate relationships found in the present study for this type of ecosystem.

Among the four climate descriptors tested here, the growing season length accounting for both temperature and water limitations $\left(G S L_{t w}\right)$ was a stronger predictor of trait-climate relationships than basic temperature and rainfall variations (i.e., MAT and MAP) commonly used to study these relationships (e.g., Moles et al., 2014; Onoda et al., 2011; but see Kikuzawa et al., 2013; Ordoñez et al., 2009). Large-scale assessments of climate control on vegetation types have already highlighted the predominant role of soil water balance (Stephenson, 1990) in addition to that of temperature (e.g., Harrison et al., 2010). Given that GSL was estimated using the same temperature and soil water content thresholds for all types of grasslands, its values cannot be considered as an absolute estimate of the time available for plant activity in a particular climate. Instead, it should be regarded as a simple way to quantify the climate constraints that are influential on primary productivity (see below). Depending on plant community, these values may change (i.e., mountain plants having lower threshold values for Growing Degree Day, and mediterranean plants having the capacity to maintain activity at lower Soil Water Content than other plants). Using the coarser climate descriptors, our study showed that leaf traits were more strongly 
(a)

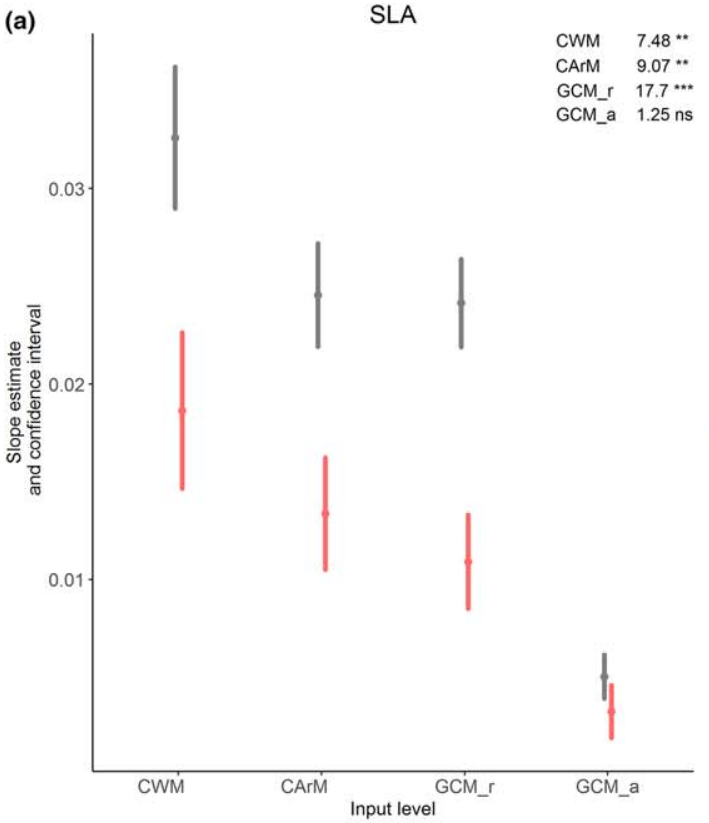

(c)

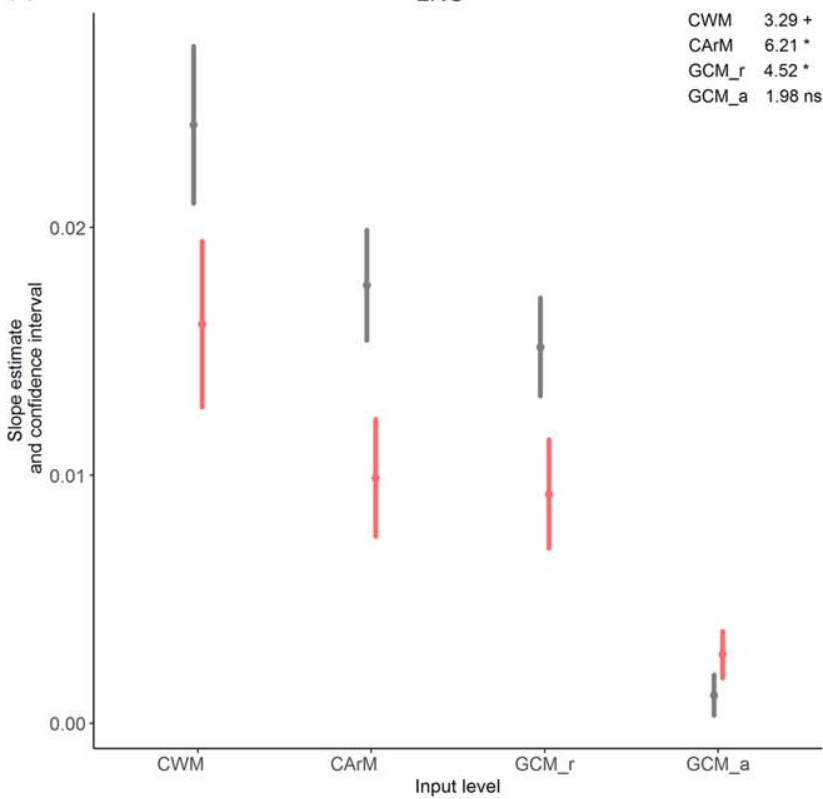

(b)

LDMC

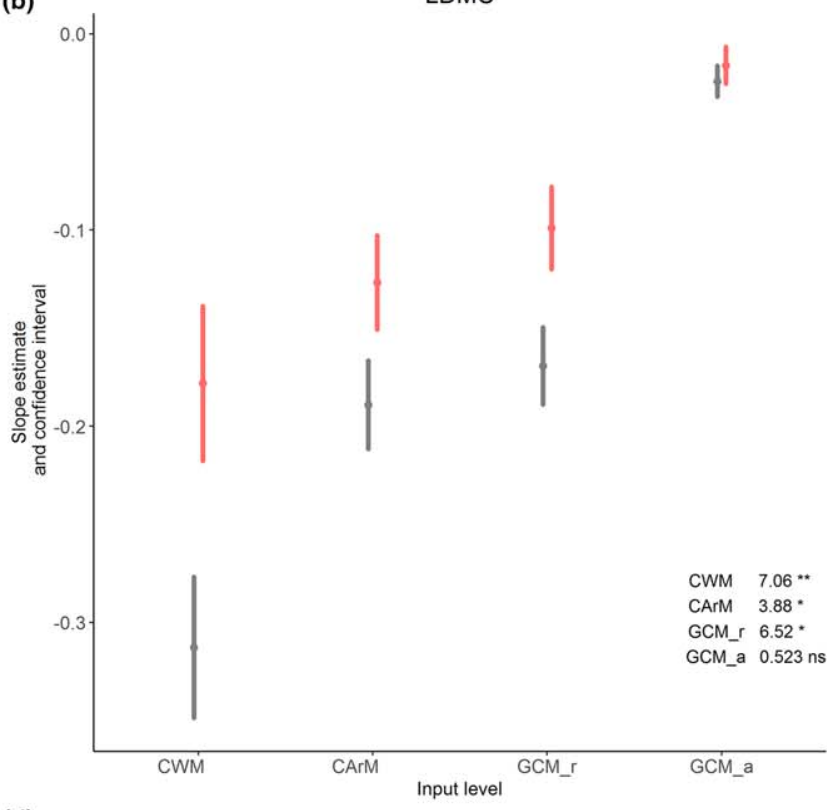

(d)

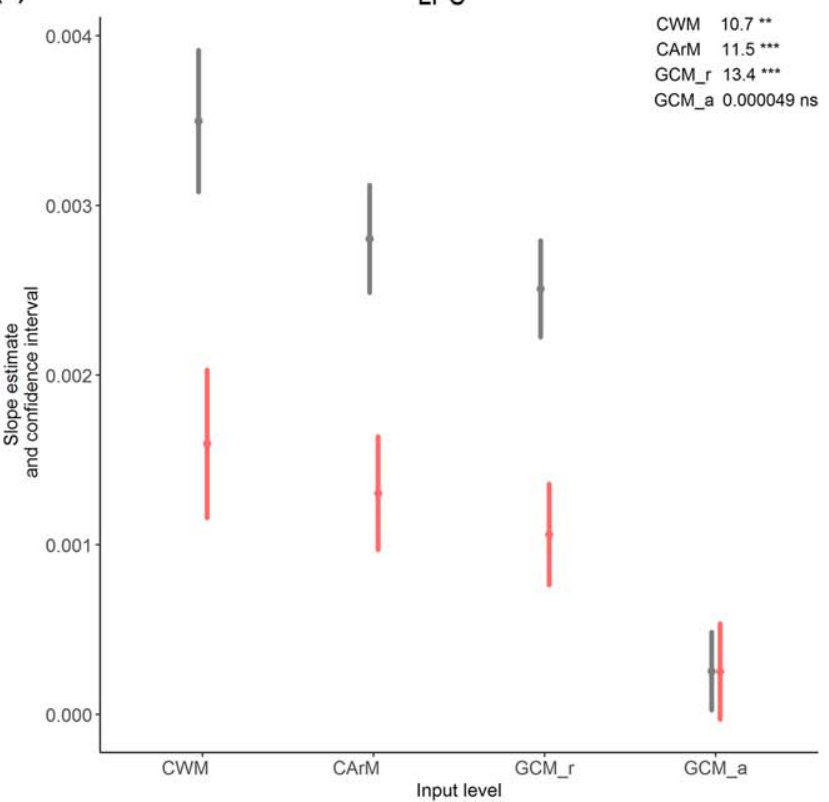

FIGURE 4 Testing differences in the slopes of trait-climate relationships for the two levels of nitrogen input ( $\mathrm{N}-$ : low input, in black; $\mathrm{N}+$ : high input, in red). Generalized least-squares (GLS) models, taking into account spatial autocorrelation, were tested for each trait between growing season length accounting for temperature limitation $\left(\mathrm{GSL}_{\mathrm{tw}}\right)$ and each trait averaging metric: community arithmetic means (CArM), community-weighted means (CWM) and grid cell mean using relevés (GCM_r) or the electronic atlas of the French flora (GCM_a). For each of the 16 models (four traits and four different metrics), we assessed whether the slope difference between the two nitrogen input levels was significant. Each panel shows the results of the analyses for one trait: LDMC = leaf dry matter content; LNC_m and LPC_m $=$ leaf nitrogen and phosphorus concentration per unit mass, respectively; SLA = specific leaf area. Vertical bars show the $95 \%$ confidence intervals of slope estimates for the corresponding GLS model. $F$ statistics from ANOVAs between the two nitrogen levels are shown. ${ }^{* * *} p<.001$. ${ }^{* *} p<.01 .{ }^{*} p<.05 .{ }^{+} p<.1 .{ }^{\mathrm{ns}} p>.1$

related to MAT than to MAP, a result already found in the most extensive study conducted to date at the species level on a worldwide scale for SLA, LNC and LPC, although with low predictive power (Moles et al., 2014).

The predominance of species with high rates of resource acquisition (high SLA, high LNC and low LDMC) under high $\mathrm{GSL}_{\mathrm{tw}}$ is consistent with the hypothesis that temperature and water-controlled estimates of GSL are proximate drivers of ecosystem primary productivity (Jolly, Nemani, \& Running, 2005). Using remotely sensed data to implement a radiation use efficiency model of gross primary productivity (GPP) indeed shows that the annual GPP of the studied grasslands is strongly related to GSL (P. Choler, C. Violle, E. Garnier and the 
DIVGRASS consortium, unpublished results), which agrees with the biogeographical trend of grassland yield observed across France (Dziewulska, 1990). The trend in trait variation detected here at a biogeographical scale complies with what is usually found at a local scale, where SLA and leaf nutrient concentrations, including nitrogen, usually increase (e.g., Chollet et al., 2014; Gebauer, Rehder, \& Wollenweber, 1988; Poorter \& de Jong, 1999), whereas LDMC decreases (e.g., Chollet et al., 2014; Hodgson et al., 2011), along productivity gradients.

Although our results agree qualitatively with those of Moles et al. (2014) in terms of the strength of the relationships between traits and temperature, on the one hand, and traits and precipitation, on the other hand (see above), the slope of most relationships was actually opposite in the two studies. Moles et al. (2014) indeed found that SLA, LNC and LPC tend to decrease with increasing temperature, whereas SLA and LNC (respectively LPC) tend to increase (respectively decrease) with increasing precipitation. Among the potential reasons for such discrepancies, two of them might be particularly relevant here. First, the range of climate conditions covered in the present study represents respectively 40 and $25 \%$ of the temperature and precipitation ranges spanned in the study by Moles et al. (2014), which included a broader range of climates from tropical to polar. Given that trait response to environmental factors might not be linear (cf. Poorter, Niinemets, Poorter, Wright, \& Villar, 2009 for a curvilinear positive response of SLA to temperature; Wang et al., 2016 for a unimodal relationship between latitude and SLA), spanning different ranges might yield different outcomes. Second, the response of traits to temperature or precipitation of $\mathrm{C}_{3}$ herbaceous species of the temperate grassland biome might be more homogeneous than that of species included in the study by Moles et al. (2014), which encompasses a wide range of species types (herbaceous, woody, deciduous and evergreens); for example, Wright et al. (2005) showed contrasting patterns of SLA variation in response to both temperature and precipitation for deciduous and evergreen shrubs and trees. More generally, inconsistencies in trait-environment relationships have been observed for a wide range of trait-environment combinations, so often that Shipley et al. (2016) identified this area of research as one of the loose foundation stones of trait-based research. These authors stressed that the poor identification of environmental factors that drive trait variations was one of the main factors explaining this state of affairs. Here, we argue that $\mathrm{GSL}_{\mathrm{tw}}$ represents an ecologically meaningful combination of local environmental parameters (e.g., soil water-holding capacity) and seasonal climatic variations that captures the spatial variation of leaf traits at a biogeographical scale better than the commonly used variables, MAT and MAP.

Differences in the slopes of trait-climate relationships between the two nitrogen levels were mainly attributable to trait differences in the lower part of the GSL $\mathrm{L}_{\mathrm{tw}}$ gradient; SLA, LNC and LPC are higher, whereas LDMC is lower in high-nitrogen grasslands, which are acknowledged effects of nutrient availability on these traits (see Garnier et al., 2016 for a synthesis). These changes between low- and high-nitrogen-input grasslands were much smaller in the upper part of the $\mathrm{GSL}_{\mathrm{tw}}$, suggesting that relaxing nutrient stress constraints either by increasing nitrogen or by improving climatic conditions for plant growth leads to comparable effects on leaf traits. Under high $\mathrm{GSL}_{\mathrm{tw}}$ and high nitrogen inputs, values of SLA, LNC and LPC reached an upper limit, suggesting that factors other than nitrogen (such as light) then become limiting or that plants primarily respond by growing to a larger size while maintaining LNC and LPC. These results differ qualitatively from those obtained in temperate forests across New Zealand, where the increase in SLA (CWM) with temperature was found to be higher with high soil phosphorus availability (Simpson et al., 2016).

The differences in the slopes of the trait-climate relationships between low- and high-nitrogen grasslands might be the consequence of differences in species turnover along the climatic gradient. Further analyses indicated that low-nitrogen grasslands had relatively high species compositional turnover along the $\mathrm{GSL}_{\mathrm{tw}}$ gradient, whereas species turnover in high-nitrogen grasslands was substantially lower, especially in the upper range of $\mathrm{GSL}_{\mathrm{tw}}$ values (Figure $\mathrm{S} 6$ in Supporting Information). Further refinements on these issues should account for (a) the impact of disturbance regimes (e.g., frequency and intensity or grazing and mowing) in addition to that of fertilization for a better assessment of the effects of grassland management on traits (e.g., Gardarin et al., 2014; Mclntyre, Lavorel, Landsberg, \& Forbes, 1999) and (b) intraspecific trait variability (Lepš, de Bello, Šmilauer, \& Doležal, 2011; Violle et al., 2012); the recent meta-analysis conducted by Siefert et al. (2015) showed that this effect accounted for approximately one-third of the total trait variation among communities on average, a proportion which decreases with increasing spatial extent. This study also showed that the effects were greater for leaf chemical than leaf morphological traits. It is thus likely that trait-environment relationships detected in the present study are noisier for LNC and LPC than for SLA and LDMC. Taking into account these two potential effects would certainly improve our understanding of trait-environment relationships, but there are currently no datasets available at regional to continental scales allowing us to do so.

By neglecting community structuring and/or local species abundance, averaging procedures using GCM and CArM tend to underestimate the effect of climate on leaf trait variations. Our results indicate that accounting for local species abundance (i.e., when CWM and CArM, on the one hand, and CWM and GCM_r, on the other hand, are compared) has the strongest effect on the detection of trait-climate relationships. Accounting for higher local abundance of stress-tolerant species (exhibiting low SLA and high LDMC) in the lower part of the $\mathrm{GSL}_{\mathrm{tw}}$ gradient and the higher local abundance of species with high rates of resource acquisition in the upper part of the GSL $L_{t w}$ gradient led to models of trait-climate relationships with stronger slopes and higher explanatory power. Stronger trait-environment relationships when species abundance is taken into account have also been found at a local scale for several factors (light, soil depth, disturbance, etc.; reviewed by Garnier et al., 2016), suggesting that more abundant species are better fitted to local environmental conditions than less abundant species (Cingolani et al., 2007; Muscarella \& Uriarte, 2016). Such effects of varying species abundance across plant communities cannot be captured by solely using species presence/absence information per grid cell, as commonly done in trait-based biogeography (e.g., Šímová et al., 
2015; Swenson et al., 2012). The study of trait-environment relationships at the species level is nonetheless relevant to address issues related to species distribution or adaptation, for example. The lack of differences in slopes of the climate-CArM and climate-GCM_r relationships suggests that considering that species are organized in communities does not carry additional information at this scale, if local species abundance is not taken into account. Finally, the lower variation in trait values observed along the gradient when the GCM_a metrics is used is likely to be related to the reduced turnover of species between grid cells compared with species turnover between plant communities. Based on these results, we conclude that species abundances within plant communities, and thus accounting for plant community organization, should not be overlooked in further attempts to predict trait-climate relationships at regional or continental scales (Reich, 2014).

\section{1 | Conclusions}

As the traits investigated are key to plant nutrient economy (Reich, 2014), our findings provide a baseline for improving process-oriented models of biogeochemical cycling in ecosystems. First, we show that the effects of climate on plant communities are better described using composite descriptors involving temperature and soil availability than coarse variables, such as mean annual temperature and/or precipitation. Second, showing that plant community is a relevant level of organization to capture trait-climate relationships should prompt Earth system modellers to pay more attention to ecological processes underlying plant community assembly and dynamics. Third, continuous trait-climate relationships allow one to account for trait variation within vegetation types (here grasslands), and it now becomes feasible to investigate the sensitivity of Earth system model outputs to improved parametrization of vegetation. Finally, the interplay of local nitrogen input and global climate drivers should be given increasing attention in future trait-based models of the biogeochemical cycles in the grassland biome that has been shaped by millennia of agro-pastoral activities (Suttie, Reynolds, \& Battello, 2005).

\section{ACKNOWLEDGMENTS}

This research is supported by the French Foundation for Research on Biodiversity (FRB; www.fondationbiodiversite.fr) in the context of the CESAB (CEntre de Synthèse et d'Analyse sur la Biodiversité) project 'Assembling, analysing and sharing data on plant functional diversity to understand the effects of biodiversity on ecosystem functioning: a case study with French Permanent Grasslands' (DIVGRASS) and by the TRY initiative on plant traits (http://www.try-db. org). The TRY initiative and database are hosted at the Max Planck Institute for Biogeochemistry, Jena, Germany, and currently supported by DIVERSITAS/Future Earth and the German Centre for Integrative Biodiversity Research (iDiv) Halle-Jena-Leipzig. C.V. and P.D. were supported by the European Research Council (ERC) Starting Grant Project 'Ecophysiological and biophysical constraints on domestication in crop plants' (Grant ERC-StG-2014-639706CONSTRAINTS).

\section{DATA ACCESSIBILITY}

Archives of data for climatic variables, nitrogen inputs and trait averages calculated using the four metrics at the $5 \mathrm{~km} \times 5 \mathrm{~km}$ pixel level will be made available in the Dryad Digital Repository (https:// datadryad.org/).

\section{ORCID}

Pierre Denelle (iD http://orcid.org/0000-0001-5037-2281

Eric Garnier (D) http://orcid.org/0000-0002-9392-5154

\section{REFERENCES}

Al Majou, H., Bruand, A., Duval, O., Le Bas, C., \& Vautier, A. (2008). Prediction of soil water retention properties after stratification by combining texture, bulk density and the type of horizon. Soil Use and Management, 24, 383-391.

Albert, C. H., Thuiller, W., Yoccoz, N. G., Soudant, A., Boucher, F., Saccone, P., \& Lavorel, S. (2010). Intraspecific functional variability: Extent, structure and sources of variation. Journal of Ecology, 98, 604-613.

Benichou, P., \& Le Breton, O. (1987). Prise en compte de la topographie pour la cartographie des champs pluviométriques statistiques. La Météorologie, 19, 23-34.

Borgy, B., Violle, C., Choler, P., Garnier, E., Kattge, J., Loranger, J., ... Viovy, N. (2017). Sensitivity of community-level trait-environment relationships to data representativeness: A test for functional biogeography. Global Ecology and Biogeography, 26, 729-739.

Braun-Blanquet, J. (1932). Plant sociology. New York, NY: McGraw-Hill.

Chapin, F. S., Zavaleta, E. S., Eviner, V. T., Naylor, R. L., Vitousek, P. M., Reynolds, H. L., ... Dìaz, S. (2000). Consequences of changing biodiversity. Nature, 405, 234-242.

Chollet, S., Rambal, S., Fayolle, A., Hubert, D., Foulquié, D., \& Garnier, E. (2014). Combined effects of climate, resource availability, and plant traits on biomass produced in a Mediterranean rangeland. Ecology, 95, 737-748

Cingolani, A. M., Cabido, M., Gurvich, D. E., Renison, D., \& Díaz, S. (2007). Filtering processes in the assembly of plant communities: Are species presence and abundance driven by the same traits? Journal of Vegetation Science, 18, 911-920.

Cunningham, S. A., Summerhayes, B., \& Westoby, M. (1999). Evolutionary divergences in leaf structure and chemistry, comparing rainfall and soil nutrient gradients. Ecological Monographs, 69, 569-588.

Dziewulska, A. (1990). The spatial differentiation of grasslands in Europe. In A. I. Breymeyer (ed.), Managed grasslands - Regional studies (pp. 1-13). Amsterdam, The Netherlands: Elsevier.

Fortunel, C., Garnier, E., Joffre, R., Kazakou, E., Quested, H., Grigulis, K., ... Zarovali, M. (2009). Leaf traits capture the effects of land use changes and climate on litter decomposability of grasslands across Europe. Ecology, 90, 598-611.

Gardarin, A., Garnier, É., Carrère, P., Cruz, P., Andueza, D., Bonis, A., ... Kazakou, E. (2014). Plant trait-digestibility relationships across management and climate gradients in permanent grasslands. Journal of Applied Ecology, 51, 1207-1217.

Garnier, E., Cortez, J., Billès, G., Navas, M.-L., Roumet, C., Debussche, M., ... Toussaint, J.-P. (2004). Plant functional markers capture ecosystem properties during secondary succession. Ecology, 85, 2630-2637.

Garnier, E., Navas, M.-L., \& Grigulis, K. (2016). Plant Functional diversity Organism traits, community structure, and ecosystem properties. Oxford, U.K.: Oxford University Press. 
Gebauer, G., Rehder, H., \& Wollenweber, B. (1988). Nitrate, nitrate reduction and organic nitrogen in plants from different ecological and taxonomic groups of Central Europe. Oecologia, 75, 371-385.

Grime, J. P. (1998). Benefits of plant diversity to ecosystems: Immediate, filter and founder effects. Journal of Ecology, 86, 902-910.

Harrison, S. P., Prentice, I. C., Barboni, D., Kohfeld, K. E., Ni, J., \& Sutra, J. P. (2010). Ecophysiological and bioclimatic foundations for a global plant functional classification. Journal of Vegetation Science, 21, 300-317.

Hodgson, J. G., Montserrat-Martí, G., Charles, M., Jones, G., Wilson, P., Shipley, B., ... Royo Pla, F. (2011). Is leaf dry matter content a better predictor of soil fertility than specific leaf area? Annals of Botany, 108, 1337-1345.

Hosmer, D. W. Jr., Lemeshow, S., \& Sturdivant, R. X. (2013). Applied logistic regression (3rd ed.). New York, NY: Wiley.

Huyghe, C. (2009). Evolution des prairies et cultures fourragères et de leurs modalités culturales et d'utilisation en France au cours des cinquante dernières années. Fourrages, 200, 407-428.

Jolly, W. M., Nemani, R., \& Running, S. W. (2005). A generalized, bioclimatic index to predict foliar phenology in response to climate. Global Change Biology, 11, 619-632.

Kattge, J., Díaz, S., Lavorel, S., Prentice, I. C., Leadley, P., Bönisch, G., .. . Wirth, C. (2011). TRY - A global database of plant traits. Global Change Biology, 17, 2905-2935.

Kazakou, E., Violle, C., Roumet, C., Navas, M.-L., Vile, D., Kattge, J., \& Garnier, E. (2014). Are trait-based species rankings consistent across data sets and spatial scales? Journal of Vegetation Science, 25, 235-247.

Kichenin, E., Wardle, D. A., Peltzer, D. A., Morse, C. W., \& Freschet, G. T. (2013). Contrasting effects of plant inter- and intraspecific variation on community-level trait measures along an environmental gradient. Functional Ecology, 27, 1254-1261.

Kikuzawa, K., Onoda, Y., Wright, I. J., \& Reich, P. B. (2013). Mechanisms underlying global temperature-related patterns in leaf longevity. Global Ecology and Biogeography, 22, 982-993.

Lavorel, S., \& Garnier, E. (2002). Predicting changes in community composition and ecosystem functioning from plant traits: Revisiting the Holy Grail. Functional Ecology, 16, 545-556.

Lavorel, S., Grigulis, K., Lamarque, P., Colace, M. P., Garden, D., Girel, J., ... Douzet, R. (2011). Using plant functional traits to understand the landscape distribution of multiple ecosystem services. Journal of Ecology, 99, 135-147.

Le Bas, C., King, D., \& Daroussin, J. (1997). A tool for estimating soil water available for plants using the 1:1,000,000 scale Soil Geographical Data Base of Europe. In K. J. Beek, K. A. de Bie, P. M. Driessen (Eds.), Geo-information for sustainable land management. International journal of aerospace survey and earth sciences (p. 10). Enschede, The Netherlands.

Lepš, J., de Bello, F., Šmilauer, P., \& Doležal, J. (2011). Community trait response to environment: Disentangling species turnover vs intraspecific trait variability effects. Ecography, 34, 856-863.

McIntyre, S., Lavorel, S., Landsberg, J., \& Forbes, T. D. A. (1999). Disturbance response in vegetation - Towards a global perspective on functional traits. Journal of Vegetation Science, 10, 621-630.

Moles, A. T., Perkins, S. E., Laffan, S. W., Flores-Moreno, H., Awasthy, M., Tindall, M. L., ... Bonser, S. P. (2014). Which is a better predictor of plant traits: Temperature or precipitation? Journal of Vegetation Science, 25, 1167-1180.

Muscarella, R., \& Uriarte, M. (2016). Do community-weighted mean functional traits reflect optimal strategies? Proceedings of the Royal Society B: Biological Sciences, 283, 20152434.
Onoda, Y., Westoby, M., Adler, P. B., Choong, A. M., Clissold, F. J., Cornelissen, J. H., ... Yamashita, N. (2011). Global patterns of leaf mechanical properties. Ecology Letters, 14, 301-312.

Ordoñez, J. C., van Bodegom, P. M., Witte, J.-P. M., Wright, I. J., Reich, P. B., \& Aerts, R. (2009). A global study of relationships between leaf traits, climate and soil measures of nutrient fertility. Global Ecology and Biogeography, 18, 137-149.

Pakeman, R. J., Eastwood, A., \& Scobie, A. (2011). Leaf dry matter content as a predictor of grassland litter decomposition: A test of the 'mass ratio hypothesis'. Plant and Soil, 342, 49-57.

Pakeman, R. J., Lepš, J., Kleyer, M., Lavorel, S., \& Garnier, E., \& the VISTA Consortium. (2009). Relative climatic, edaphic and management controls of plant functional trait signatures. Journal of Vegetation Science, 20, 148-159.

Pakeman, R. J., \& Quested, H. M. (2007). Sampling plant functional traits: What proportion of the species need to be measured? Applied Vegetation Science, 10, 91-96.

Palacio-Rabaud, V. (2000). La conduite des prairies en France: Pratiques intensives et rendements élevés dans le Nord-Ouest. Agreste Cahiers, $4,15-26$.

Piedallu, C., \& Gégout, J.-C. (2008). Efficient assessment of topographic solar radiation to improve plant distribution models. Agricultural and Forest Meteorology, 148, 1696-1706.

Pontes, L. D. S., Soussana, J. F., Louault, F., Andueza, D., \& Carrère, P. (2007). Leaf traits affect the above-ground productivity and quality of pasture grasses. Functional Ecology, 21, 844-853.

Poorter, H., \& de Jong, R. (1999). A comparison of specific leaf area, chemical composition and leaf construction costs of field plants from 15 habitats differing in productivity. New Phytologist, 143, 163-176.

Poorter, H., Niinemets, Ü., Poorter, L., Wright, I. J., \& Villar, R. (2009). Causes and consequences of variation in leaf mass per area (LMA): A meta-analysis. New Phytologist, 182, 565-588.

R Development Core Team. (2016). R: A language and environment for statistical computing. Vienna, Austria: R Foundation for Statistical Computing.

Read, Q. D., Moorhead, L. C., Swenson, N. G., Bailey, J. K., \& Sanders, N. J. (2014). Convergent effects of elevation on functional leaf traits within and among species. Functional Ecology, 28, 37-45.

Reich, P. B. (2014). The world-wide 'fast-slow' plant economics spectrum: A traits manifesto. Journal of Ecology, 102, 275-301.

Sala, O. E., Austin, A. T., \& Vivanco, L. (2001). Temperate grassland and shrubland ecosystems. In S. A. Levin (Ed.), Encyclopedia of biodiversity (pp. 627-635). San Diego, CA: Academic Press.

Sandel, B., Goldstein, L. J., Kraft, N. J., Okie, J. G., Shuldman, M. I., Ackerly, D. D., ... Suding, K. N. (2010). Contrasting trait responses in plant communities to experimental and geographic variation in precipitation. New Phytologist, 188, 565-575.

Shipley, B., De Bello, F., Cornelissen, J. H. C., Laliberté, E., Laughlin, D. C., \& Reich, P. B. (2016). Reinforcing loose foundation stones in traitbased plant ecology. Oecologia, 180, 923-931.

Shipley, B., Lechowicz, M. J., Wright, I. J., \& Reich, P. B. (2006). Fundamental trade-offs generating the worldwide leaf economics spectrum. Ecology, 87, 535-541.

Siefert, A., Violle, C., Chalmandrier, L., Albert, C. H., Taudiere, A., Fajardo A., ... Wardle, D. A. (2015). A global meta-analysis of the relative extent of intraspecific trait variation in plant communities. Ecology Letters, 18, 1406-1419.

Šímová, I., Violle, C., Kraft, N. J. B., Storch, D., Svenning, J.-C., Boyle, B., ... Enquist, B. J. (2015). Shifts in trait means and variances in North American tree assemblages: Species richness patterns are loosely related to the functional space. Ecography, 38, 649-658. 
Simpson, A. H., Richardson, S. J., \& Laughlin, D. C. (2016). Soil-climate interactions explain variation in foliar, stem, root and reproductive traits across temperate forests. Global Ecology and Biogeography, 25, 964-978.

Stephenson, N. L. (1990). Climatic control of vegetation distribution: The role of the water balance. The American Naturalist, 135, 649-670.

Suding, K. N., Lavorel, S., Chapin, F. S. III, Cornelissen, J. H. C., Díaz, S., Garnier, E., ... Navas, M.-L. (2008). Scaling environmental change through the community-level: A trait-based response-and-effect framework for plants. Global Change Biology, 14, 1125-1140.

Suttie, J. M., Reynolds, S. G., \& Battello, C. (2005). Grasslands of the world. Roma: FAO.

Swenson, N. G., Enquist, B. J., Pither, J., Kerkhoff, A. J., Boyle, B., Weiser, M. D., ... Nolting, K. M. (2012). The biogeography and filtering of woody plant functional diversity in North and South America. Global Ecology and Biogeography, 21, 798-808.

Turc, L. (1961). Evaluation de besoins en eau d'irrigation, évapotranspiration potentielle. Annales Agronomiques, 12, 13-49.

van Ommen Kloeke, A. E. E., Douma, J. C., Ordoñez, J. C., Reich, P. B., \& van Bodegom, P. M. (2012). Global quantification of contrasting leaf life span strategies for deciduous and evergreen species in response to environmental conditions. Global Ecology and Biogeography, 21, 224-235.

Verheijen, L. M., Brovkin, V., Aerts, R., Bönisch, G., Cornelissen, J. H. C., Kattge, J., ... van Bodegom, P. M. (2013). Impacts of trait variation through observed trait-climate relationships on performance of an Earth system model: A conceptual analysis. Biogeosciences, 10, 5497-5515.

Violle, C., Choler, P., Borgy, B., Garnier, E., Amiaud, B., Debarros, G., ... Viovy, N. (2015). Vegetation ecology meets ecosystem science: Permanent grasslands as a functional biogeography case study. Science of the Total Environment, 534, 43-51.

Violle, C., Enquist, B. J., McGill, B. J., Jiang, L., Albert, C. H., Hulshof, C., ... Messier, J. (2012). The return of the variance: Intraspecific variability in community ecology. Trends in Ecology and Evolution, 27, 244-252.

Violle, C., Reich, P. B., Pacala, S. W., Enquist, B. J., \& Kattge, J. (2014). The emergence and promise of functional biogeography. Proceedings of the National Academy of Sciences USA, 111, 13690-13696.

Wang, R., Yu, G., He, N., Wang, Q., Zhao, N., \& Xu, Z. (2016). Latitudinal variation of leaf morphological traits from species to communities along a forest transect in eastern China. Journal of Geographical Sciences, 26, 15-26.

Wang, Y. P., Lu, X. J., Wright, I. J., Dai, Y. J., Rayner, P. J., \& Reich, P. B. (2012). Correlations among leaf traits provide a significant constraint on the estimate of global gross primary production. Geophysical Research Letters, 39, L19405.

Wright, I. J., Reich, P. B., Cornelissen, J. H. C., Falster, D. S., Groom, P. K., Hikosaka, K., ... Westoby, M. (2005). Modulation of leaf economic traits and trait relationships by climate. Global Ecology and Biogeography, 14, 411-421.

Wright, I. J., Reich, P. B., Westoby, M., Ackerly, D. D., Baruch, Z., Bongers, F., ... Villar, R. (2004). The worldwide leaf economics spectrum. Nature, 428, 821-827.

Zuur, A. F., leno, E. N., Walker, N. J., Saveliev, A. A., \& Smith, G. M. (2009). Mixed effects models and extensions in ecology with R. New York, NY: Springer.

\section{BIOSKETCH}

The DIVGRASS consortium is a CESAB working group involving experts in grassland ecology, soil science, ecosystem modelling and conservation management. The objective of the consortium is to combine existing data on the plant diversity of French permanent grasslands to gain a better understanding of the links between biodiversity and ecosystem functioning.

\section{SUPPORTING INFORMATION}

Additional Supporting Information may be found online in the supporting information tab for this article.

How to cite this article: Borgy B, Violle C, Choler P, et al. Plant community structure and nitrogen inputs modulate the climate signal on leaf traits. Global Ecol Biogeogr. 2017;26:1138-1152. https://doi.org/10.1111/geb.12623 


\section{APPENDIX : SOURCES FOR VEGETATION RELEVÉS AND TRAIT DATA}

TABLE A1 List of sources for vegetation relevés

\begin{tabular}{|c|c|c|}
\hline Dataset & $\begin{array}{l}\text { Number of relevés in } \\
\text { the dataset }\end{array}$ & Sources \\
\hline Conservatoires Botaniques Nationaux (CBN) et Fédération des CBNs & 7,765 & \\
\hline UCBN (a dataset of permanent grasslands in the north of France) & 389 & \\
\hline DivHerbe & 60 & Gardarin et al., 2014 \\
\hline Total & 20,368 & \\
\hline
\end{tabular}

Note. References for vegetation relevés.

Brisse et al. (1995a) Brisse, H., de Ruffray, P., Grandjouan, G., \& Hoff, M. (1995). The phytosociological database SOPHY - Part II: Socio-ecological classification of the relevés. In 4th International Workshop 'European Vegetation Survey' (IAVS) (Vol. 53, pp. 191-223). Rome, Italy.

Brisse et al. (1995b)

Brisse, H., de Ruffray, P., Grandjouan, G., \& Hoff, M. (1995). The Phytosociological database SOPHY - Part I: Calibration of indicator plants. In 4th International Workshop 'European Vegetation Survey' (IAVS) (Vol. 53, pp. 177-190). Rome, Italy.

Gardarin et al. (2014)

Gardarin, A., Garnier, E., Carrère, P., Cruz, P., Andueza, D., Bonis, A., ... Kazakou, E. (2014). Plant traitdigestibility relationships across management and climate gradients in permanent grasslands. Journal of Applied Ecology, 51, 1207-1217.

Plantureux and Amiaud (2010)

Plantureux, S., \& Amiaud, B. (2010). e-FLORA-sys, a website tool to evaluate agronomical and environmental value of grasslands. In 23rd EGF General Meeting, Kiel, Germany.

TABLE A2 List of sources for trait data

\begin{tabular}{lll}
\hline Trait & Database(s) & Source(s) \\
\hline SLA & TRY, ANDROSACE, DivHerbe, VISTA & Bahn et al., 1999; Bernard-Verdier et al., 2012; Cornelissen, 1996; Cornelissen et al., \\
& & 2003a, 2004; Cornwell et al., 2008; Díaz et al., 2004; Fonseca et al., 2000; Garnier et al., \\
& 2004, 2007; Han et al., 2005; Kattge et al., 2009; Kleyer et al., 2008; Laughlin et al., & 2010; Ordoñez et al., 2010; Pyankov et al., 1999; Quested et al., 2003; Shipley, 1995; \\
& Shipley \& Vu, 2002; Vile et al., 2006; Wright et al., 2004, 2006
\end{tabular}

Note. References for trait data. DivHerbe, database from the "Structure, diversité et fonctionnement: des clés multi-échelles pour la gestion des prairies permanentes" project; VISTA, data base from the "Vulnerability of ecosystem services to land use change in traditional agricultural landscapes" project.

Bahn et al. (1999)

Bahn, M., Wohlfahrt, G., Haubner, E., Horak, I., Michaeler, W., Rottmar, K., ... Cernusca, A. (1999). Leaf photosynthesis, nitrogen contents and specific leaf area of 30 grassland species in differently managed mountain ecosystems in the Eastern Alps. In A. Cernusca, U. Tappeiner, \& N. Bayfield (Eds.), Land-use changes in European mountain ecosystems. ECOMONT - Concept and results (pp. 247-255). Berlin, Germany: Blackwell Wissenschaft.

Bernard-Verdier et al. (2012) Bernard-Verdier, M., Navas, M. L., Vellend, M., Violle, C., Fayolle, A., \& Garnier, E. (2012). Community assembly along a soil depth gradient: Contrasting patterns of plant trait convergence and divergence in Mediterranean rangelands. Journal of Ecology, 100, 1422-1433.

Cornelissen (1996)

Cornelissen, J. H. C. (1996). An experimental comparison of leaf decomposition rates in a wide range of temperate plant species and types. Journal of Ecology, 84, 573-582. 
TABLE A2 (Continued)

Cornelissen et al. (2003)

Cornelissen, J. H. C., Cerabolini, B., Castro-Diez, P., Villar-Salvador, P., Montserrat-Marti, G., Puyravaud, J. P., ... Aerts, R. (2003). Functional traits of woody plants: Correspondence of species rankings between field adults and laboratory-grown seedlings? Journal of Vegetation Science, 14, 311-322.

Cornelissen et al. (2004)

Cornelissen, J. H. C., Quested, H. M., Gwynn-Jones, D., Van Logtestijn, R. S. P., De Beus, M. A. H., Kondratchuk, A., . Aerts, R. (2004). Leaf digestibility and litter decomposability are related in a wide range of subarctic plant species and laboratory-grown seedlings? Journal of Vegetation Science, 18, 779-786.

Cornwell et al. (2008) C Cornwell, W. K., Cornelissen, J. H. C., Amatangelo, K., Dorrepaal, E., Eviner, V. T., Godoy, O., ... Westoby, M. (2008). Plant species traits are the predominant control on litter decomposition rates within biomes worldwide. Ecology Letters, 11, 1065-1071.

Craine et al. (2005)

Craine, J. M., Lee, W. G., Bond, W. J., Williams, R. J., \& Johnson, L. C. (2005). Environmental constraints on a global relationship among leaf and root traits of grasses. Ecology, 86, 12-19.

Craine et al. (2009) Craine, J. M., Elmore, A. J., Aidar, M. P. M., Bustamante, M., Dawson, T. E., Hobbie, E. A., ... Wright, I. J. (2009). Global patterns of foliar nitrogen isotopes and their relationships with climate, mycorrhizal fungi, foliar nutrient concentrations, and nitrogen availability. New Phytologist, 183, 980-992.

Díaz et al. (2004)

Díaz, S., Hodgson, J. G., Thompson, K., Cabido, M., Cornelissen, J. H. C., Jalili, A., ... Zak, M. R. (2004). The plant traits that drive ecosystems: Evidence from three continents. Journal of Vegetation Science, 15, 295-304.

Fonseca et al. (2000) Fonseca, C. R., Overton, J. M., Collins, B., \& Westoby, M. (2000). Shifts in trait-combinations along rainfall and phosphorus gradients. Journal of Ecology, 88, 964-977.

Garnier et al. (2004)

Garnier, E., Cortez, J., Billès, G., Navas, M.-L., Roumet, C., Debussche, ... Toussaint, J.-P. (2004). Plant functional markers capture ecosystem properties during secondary succession. Ecology, 85, 2630-2637.

Garnier et al. (2007) Garnier, E., Lavorel, S., Ansquer, P., Castro, H., Cruz, P., Dolezal, J., .. Zarovali, M. P. (2007). Assessing the effects of landuse change on plant traits, communities and ecosystem functioning in grasslands: A standardized methodology and lessons from an application to 11 European sites. Annals of Botany, 99, 967-985.

Han et al. (2005)

Han, W. X., Fang, J. Y., Guo, D. L., \& Zhang, Y. (2005). Leaf nitrogen and phosphorus stoichiometry across 753 terrestrial plant species in China. New Phytologist, 168, 377-385.

Kattge et al. (2009) Kattge, J., Knorr, W., Raddatz, T., \& Wirth, C. (2009). Quantifying photosynthetic capacity and its relationship to leaf nitrogen content for global-scale terrestrial biosphere models. Global Change Biology, 15, 976-991.

Kazakou et al. (2006)

Kazakou, E., Vile, D., Shipley, B., Gallet, C., \& Garnier, E. (2006). Co-variations in litter decomposition, leaf traits and plant growth in species from a Mediterranean old-field succession. Functional Ecology, 20, 21-30.

Kleyer et al. (2008) Kleyer, M., Bekker, R. M., Knevel, I. C., Bakker, J. P., Thompson, K., Sonnenschein, M., ... Peco, B. (2008). The LEDA Traitbase: A database of life-history traits of the Northwest European flora. Journal of Ecology, 96, 1266-1274.

Laughlin et al. (2010) Laughlin, D. C., Leppert, J. J., Moore, M. M., \& Sieg, C. H. (2010). A multi-trait test of the leaf-height-seed plant strategy scheme with 133 species from a pine forest flora. Functional Ecology, 24, 493-501.

Ordoñez et al. (2010) Ordoñez, J. C., van Bodegom, P. M., Witte, J. P. M., Bartholomeus, R. P., van Hal, J. R., \& Aerts, R. (2010). Plant strategies in relation to resource supply in mesic to wet environments: Does theory mirror nature? The American Naturalist, 175, 225-239.

Pyankov et al. (1999) Pyankov, V. I., Kondratchuk, A. V., \& Shipley, B. (1999). Leaf structure and specific leaf mass: The alpine desert plants of the Eastern Pamirs, Tadjikistan. New Phytologist, 143, 131-142.

Quested et al. (2003) Quested, H. M., Cornelissen, J. H. C., Press, M. C., Callaghan, T. V., Aerts, R., Trosien, F., ... Jonasson, S. E. (2003). Decomposition of sub-arctic plants with differing nitrogen economies: A functional role for hemiparasites. Ecology, 84 , 3209-3221.

Shipley (1995)

Shipley, B. (1995). Structured interspecific determinants of specific leaf-area in 34 species of herbaceous angiosperms. Functional Ecology, 9, 312-319.

Shipley and Vu (2002) Shipley, B., \& Vu, T. T. (2002). Dry matter content as a measure of dry matter concentration in plants and their parts. New Phytologist, 153, 359-364.

Vile et al. (2006)

Vile, D., Shipley, B., \& Garnier, E. (2006). A structural equation model to integrate changes in functional strategies during old-field succession. Ecology, 87, 504-517.

Wright et al. (2006) Wright, I. J., Reich, P. B., Atkin, O. K., Lusk, C. H., Tjoelker, M. G., \& Westoby, M. (2006). Irradiance, temperature and rainfall influence leaf dark respiration in woody plants: Evidence from comparisons across 20 sites. New Phytologist, 169, 309-319.

Wright et al. (2004)

Wright, I. J., Reich, P. B., Westoby, M., Ackerly, D. D., Baruch, Z., Bongers, F., ... Villar, R. (2004). The worldwide leaf economics spectrum. Nature, 428, 821-827.

For traits and relevés, plant taxonomy followed the TaxRef4 referential (Museum National d'Histoire Naturelle, 2013; http://inpn.mnhn.fr/telechargement/ referentielEspece/referentielTaxo). 